\title{
A EDUCAÇÃO RURAL NO PERÍODO DE 1946-1960 EM GUARAPUAVA E NO PARANÁ
}

\author{
Rodrigo dos Santos ${ }^{1}$ \\ Angela Maria Hidalgo ${ }^{2}$
}

\section{RESUMO}

O artigo analisa a Educação Rural no Estado do Paraná, nas duas gestões do governador do Paraná, Moysés Lupion. Identifica-se que, nos anos 1946-1950 e 1956-1960, se instalou um programa educacional denominado desenvolvimento de comunidade, cujo componente principal foi a educação rural. Nesta fase, havia uma preocupação com o campo, que se intensificou nos mandatos de Lupion. Na região de Guarapuava foram investidos recursos do governo federal e estadual para a expansão das escolas rurais, inclusive para a instalação de uma instituição secundária de formação de professores.

Palavras-chave: Desenvolvimentismo; Guarapuava; História da Educação; Políticas Educacionais; Políticas Públicas.

\section{RURAL EDUCATION IN THE PERIOD 1946-1960 AND GUARAPUAVA PARANÁ}

\begin{abstract}
The article analyzes the Rural Education in the State of Paraná, in the presidencies of the governor of Paraná, Moyses Lupion. Identifies that, in the years 1946-1950 and 19561960, settled an educational program called community development, whose main component was the rural education. At this stage, there was a concern with the field, which has intensified in terms of Lupion. In the region of Guarapuava resources have been invested in the federal and state government for the expansion of rural schools, including the installation of a secondary institution for teacher education.

Keywords: Developmentalism; Guarapuava; History of Education; Educational Policies; Public Policies.
\end{abstract}

\section{Introdução}

A presente pesquisa objetiva dentro do tema História e Educação, analisar a materialização das medidas governamentais educacionais para a área rural, nas gestões (1946-1950 e 1956-1960) de Moysés Lupion, como governador do Estado do Paraná. O trabalho divide-se em três momentos distintos. No primeiro aponta elementos econômicos e políticos do país, e como se desenvolveu a Educação Rural no Brasil. No segundo, as mesmas questões são desenvolvidas no Paraná, e no terceiro apresenta a constituição da Educação Rural para Guarapuava. Explicita-se a relação entre os investimentos realizados nas esferas municipal, estadual e federal; na construção de escolas e no aumento de recursos para esta modalidade de ensino. 
O Brasil na década de 1930 iniciou o processo denominado de nacional desenvolvimentismo em que temos a mudança de uma política econômica predominantemente agrícola para uma de industrialização através de convênios com outros países. A educação foi considerada elemento central para a formação de trabalhadores nas áreas rurais, atendendo às necessidades de modernização das regiões agrícolas do país. Foram desenvolvidos programas que visavam não apenas a fixação dos trabalhadores no campo, mas a melhoria das condições de vida destas populações evitando a emergência de movimentos contra hegemônicos.

No Paraná, com o interventor Manoel Ribas, o Estado ${ }^{3}$ atraiu novas pessoas para as áreas do Norte e Sudoeste. Em sequência a política de Moyses Wille Lupion, nos seus dois mandatos, foi mais contundente na povoação e na distribuição de recursos para manter a população rural no campo. Criou-se para esta finalidade uma rede de ensino expandida para a zona rural, e um sistema de rodovias interligando as regiões do Estado.

O educador Erasmo Pilotto, secretário dos mandatos do governo de Lupion, atuou na expansão das escolas rurais e nos cursos de formação de professores do Paraná. Entre as medidas adotadas por Pilloto no período de 1948 aponta-se a reorganização da Secretaria de Educação e Cultura, a elaboração do Anteprojeto da lei Orgânica da Educação e os Programas das Escolas Normais Regionais.

Guarapuava, nesse contexto desenvolvimentista, teve um papel fundamental na construção de escolas do campo paranaense, pela sua grande extensão territorial e por ser uma cidade agrícola até a década de 1970. O governo estadual destinou vários recursos para a manutenção das escolas rurais na região ${ }^{4}$.

O que permeou essas relações econômicas, políticas e sociais, foram os conflitos da população agrícola/rural por melhores condições de vida e dignidade. Não bastava um pequeno pedaço de terra, ou propiciar pequenas benfeitorias para conter a migração para a cidade. A situação de miserabilidade fomentava movimentos de contestação, a exemplo das ligas camponesas e sindicatos rurais no país, assim como a Revolta de Porecatu nos anos de 1940 no Paraná. Os programas impostos pelo governo objetivavam, para além da melhoria das condições de existência, a desarticulação destes movimentos. Pretendia-se, com essa modalidade de ensino, promover nas áreas rurais/ agrícolas do país, a formação de sujeitos com uma mentalidade voltada para a participação produtiva e social, dentro dos limites do modo de produção capitalista.

Algumas críticas aos projetos de educação rural implantados nos anos de 1950 consideram esta pelo seu caráter pejorativo, por apresentar uma concepção negativa dos sujeitos do campo suprimindo sua parcela de protagonismo (CALDART, 2009). Por outro Bezerra Neto (2010) defende que as propostas atuais para a educação do campo na atualidade, mesmo as defendidas pelos movimentos sociais, apresentam elementos bastante próximos aos apresentados nos programas desta década. Podemos mencionar a Campanha Nacional de Educação Rural e o Projeto de Desenvolvimento de Comunidade inspirados nas extensões mexicanas que tinham como objetivo a fixação dos camponeses ao campo, levar um conjunto de conhecimentos que pudesse melhorar os padrões de produção e o nível de vida das populações, respeitando as especificidades das populações locais e, buscando desenvolver os trabalhos a partir do protagonismo das lideranças locais, como será demonstrado neste trabalho. Se considerarmos que todo este esforço empreendido pelos governos nos diferentes âmbitos da federação, esteve pautado, sobretudo pela tentativa de neutralização das lutas campesinas que pudessem desencadear tentativas de alterações nas relações de produção, cabe ressaltar a importância de análise das propostas educativas deste período. Esforço realizado neste estudo em que iremos apresentar a consonância das medidas tomadas tanto em âmbito federal, como estadual e municipal. 


\section{Política e econômica do Brasil pós 1930}

Mudanças significativas foram desencadeadas nos vários aparelhos do Estado brasileiro, no período pós 1930; a economia brasileira mudou o foco de exportadora de produtos agrícolas buscando a instalação de indústrias não apenas de matérias primas. Conforme Furtado (1998, p. 17-20) era inadmissível um país como o Brasil depender essencialmente da agricultura para seu desenvolvimento por causa da diversidade das classes sociais que o compunha. A busca pela industrialização tinha como objetivo resolver os problemas da sociedade brasileira que era composta em sua maioria por classes com baixo poder aquisitivo, ou seja, tinha-se a mentalidade que a industrialização iria resolver o problema das desigualdades sociais.

O economista Francisco de Oliveira (2003, p. 35) apresenta o golpe do Estado Novo como um divisor político e econômico. Para ele houve uma ruptura significativa com o advento do golpe do Estado Novo, a economia passou de base agroexportadora, para a predominância de uma estrutura urbana industrial. Torna-se pertinente salientar que em 1956, pela primeira vez a renda do setor industrial superou a agricultura.

O pesquisador Bielschowski (2004) também desenvolve a mesma premissa desenvolvimentista apontada por Furtado e Oliveira, a superação de uma ideologia subdesenvolvida (substituição do agrícola) pela industrialização. A categoria de análise contemplada pelo autor foi: "O conceito de 'desenvolvimentismo', definido como a ideologia de superação do subdesenvolvimentismo através de uma industrialização capitalista" (BIELSCHOWSKI, 2004, p. 431). Considerado o embrião da configuração do nosso sistema produtivo. Através de compendio de ideias sobre o tema este autor enaltece que a preocupação na industrialização brasileira teve seu início entre 1930 e 1945, o apogeu nos anos de 1950 e seu declínio nos anos de 1960.

No aspecto político temos no período de 1945 o populismo fomentado por Getúlio Vargas, a criação de leis trabalhistas e a superação da política do Café com Leite elencando este como presidente, portanto uma política deslocada do centro do país (São Paulo- Minas Gerais). Também é pertinente para a compreensão do período a eleição de Eurico Dutra como presidente em 1956, explicitando a deposição dos ditadores e o apogeu do desenvolvimentismo com Juscelino Kubitschek em 1960. Percebe-se a nova dinâmica do Estado brasileiro, com as mudanças nos aparelhos estatais: tanto políticas, como econômicas, e consequentemente sociais.

No aspecto econômico a industrialização consolidou-se com Vargas tendo seu apogeu em 1960, com Juscelino Kubitschek. Rodrigues (1987, p. 40) afirma que no governo de Kubitschek ocorreu a implementação do projeto de desenvolvimento industrial capitalista no país. A denominação de auge do período desenvolvimentista pode ser agraciada para Juscelino, principalmente pelo plano de metas, diante a necessidade de se criar uma infraestrutura no país com a mudança Capital Federal, através de investimentos de capital estrangeiro nos setores dinâmicos da economia.

Diante disso, vários acordos foram firmados entre os governantes brasileiros e os estadunidenses. Acordos iniciados com Getúlio Vargas como a construção da Companhia Siderurgia Nacional. É relevante mencionarmos os acordos nos aparelhos educacionais principalmente para a área rural do país. 
No período final da Segunda Guerra Mundial, 1945, com a declaração da Guerra Fria $^{5}$ a ONU,(Organização das Nações Unidas), criou programas de auxílio aos países pobres. Estes auxílios financeiros foram acompanhados de projetos educativos. Como afirma Ammann (1997, p. 30): "os povos famintos têm mais receptividade à propaganda comunista". Para tanto, o país que se sobressaiu na Guerra, os Estados Unidos, conseguiu fortalecimento político e econômico, como potência hegemônica, tinha obrigação de auxiliar financeiramente os países pobres, em especial a América Latina.

No Brasil, os auxílios começaram antes mesmo do fim da segunda Guerra Mundial, como já mencionado; além do acordo para a construção da Companhia Siderúrgica Nacional, ocorreu em 1942 uma ajuda para incremento da produção de alimentos, ainda no governo Vargas (AMMANN, 1997, p. 29-30).

O acordo para o Brasil tinha como principio primordial evitar o êxodo rural da população que ansiava pela cidade, por melhores condições de vida. $\mathrm{O}$ analfabetismo do campo representava um fator de atraso do país com relação aos demais. A educação da população rural despontava como uma solução aos problemas, no entanto, os programas instituídos constituíram-se em um mínimo de instrução para essa população que precisava de trabalho, saúde e noções de higiene. A preparação para o trabalho viria com a qualificação técnica (AMMANN, 1997, p. 31).

Portanto as propostas de educação popular no período não se constituíram por iniciativa "dos sujeitos coletivos que começam a se organizar nos processos de luta pelas reformas de base, entre elas a Reforma Agrária" (RIBEIRO, 2008, p. 56). As propostas educativas para os camponeses, neste período, foram elaboradas por interlocutores de forma articulada aos projetos populistas-desenvolvimentistas e à luta pela escolarização de jovens e adultos do final dos anos 1940 e início dos anos 50, por ação das esquerdas marxistas, que apostavam na "criação de programas para adultos a partir das organizações de massa e com vista a sua multiplicação e fortalecimento" (PAIVA, 2003, p. 188).

A Organização das Nações Unidas para Agricultura e Alimentação - FAO, organiza em 1948, a Primeira Conferência Latino-Americana de Nutrição em


Geógrafo atua no país no fomento da educação rural difundindo os princípios dos organismos internacionais para a educação rural no período. Lança, em 1951, o livro "Geopolítica da Fome", e torna-se Presidente do Conselho Executivo da FAO entre 1952 e 1956 e, promove, no Rio de Janeiro, uma mesa redonda sobre a Educação Rural com a participação de representantes da FAO e de integrantes da Comissão de Educação Rural em Itaperuna, Estado do Rio de Janeiro. Neste seminário os princípios para esta modalidade de ensino foram explicitados: a fixação do homem ao meio rural por meio de alterações das condições sócio-econômicas; promoção de mudanças na mentalidade dos sujeitos para a formação de indivíduos ativos e com desejo de mudanças da realidade em que está inserido; o uso de estratégias, como planos de intervenção locais, flexíveis e interdisciplinares, voltados para a formação de líderes locais e de escolas normais rurais para a formação de educadores (CPDOC, 1951).

No mesmo ano da $9^{a}$ Conferência Internacional Americana de Bogotá, ainda em 1948, destacamos a realização do Seminário Regional de Educación en la América Latina, na cidade de Caracas promovida pelo Departamento de Assuntos Culturales da Unión Paranamericana - OEA, UNESCO e Governo da Venezuela. No documento produzido pelo grupo de trabalho em Educação Rural neste seminário explicita-se o objetivo de divulgação dos acordos das conferências de Chapultepec e Bogotá e os princípios 
democráticos das Nações Unidas, como o maior meio de orientar a ação e a conduta do magistério da América" (União Paranamericana, 1949, p. 59). A democracia é apresentada como "elemento essencial de nossa cultura" é apresentada em contraponto às "forças antidemocráticas", que segundo este documento da União Panamericana (1949), "estão sempre em busca de oportunidades favoráveis para colocar em ação um plano estratégico cuidadosamente elaborado" para adentrar nestas sociedades, quando apresentam fissuras provocadas pelas crises econômicas e políticas. Ou seja, supõe-se que as crises, de natureza econômica e política são resultado de uma imperfeição na implementação de um modelo democrático de sociedade, que é o capitalismo. Ou seja, a democracia, como "uma conquista cultural realizada na esfera das relações humanas e nos valores sociais", transformada em "fé democrática", deverá "renovar-se de geração em geração por meio da educação organizada"(UNIÃO PANAMERICANA, 1949, p.19).

Também destacamos as recomendações para que os países representados no evento, constituam centros de informação pedagógicas, que reúnam informações sobre "os movimentos educativos de cada um dos países da América Latina", e ainda, "todas as publicações relacionadas com o movimento educativo (leis, regulamentos, recomendações, livros, textos, etc.)" (UNIÃO PANAMERICANA, 1949, p. 60). Destacamos que transparece nesta recomendação uma preocupação em monitorar, nos diferentes países, o pensamento pedagógico e as medidas tomadas pelos governos na organização da educação.

Fica explícito o uso da educação como estratégia de controle dos movimentos educativos contra-hegemônicos na região, assim como a criação de estratégias para a elaboração de princípios educativos focados na perspectiva democrática liberal que fossem legitimados pela participação dos educadores-pesquisadores nos seminários e difundidos para a criação de um consenso social em torno destes.

Em 1949, com o patrocínio do governo brasileiro, da Unesco, e da União PanAmericana, um Seminário para a Educação de adultos, reunindo profissionais com experiência em extensões rurais em outros países. Paralelamente a isso foi criado o Serviço Rural: "desenvolveram projetos para a preparação de técnicos destinados à educação de base rural e programas de melhoria de vida dos rurícolas" (IANNI, 2005, p. 36). Estes projetos também se preocupavam em trazer atrativos culturais para as áreas agrícolas através da televisão, do cinema, do teatro, do esporte.

Se inicialmente a educação das populações rurais efetivou-se por intermédio de projetos de educação de adultos, em 1952 é criada a Campanha Nacional de Educação Rural (CNER), regulamentada, com verbas próprias, somente a partir de 1956, assume a filosofia da educação como propulsora do desenvolvimento econômico e social. Atendendo aos apelos da ONU, implementa os Centros Sociais de Comunidade e as Missões Rurais, como mecanismos de promoção do progresso e desenvolvimento social das populações rurais (AMMANN, 1997).

A "Campanha Nacional de Educação Rural, na qual se reflete a reorientação dos organismos internacionais, em relação à educação dos adultos analfabetos, instalando suas missões em pequenas unidades do interior do país" (PAIVA, 2003, p. 189).

A ONU, fomentadora do programa, determinava a homogeneidade dos projetos: "Essa visão da integração preconizada pela ONU não levava em conta as contradições e desigualdades das sociedades, colocando no desenvolvimento das comunidades o meio de integrá-las à vida nacional" (BARREIRO, 1989, p.95).

Por outro lado, no caso da UNESCO, destacamos a participação de Anísio Teixeira como Conselheiro em Educação, no ano de 1946, com incumbência de colaborar "na elaboração de um relatório que sirva de plano para a agenda da I Conferência da UNESCO em novembro, em Paris" (HUXLEY, 1946). Anísio Teixeira teve atuação decisiva no país, 
no processo de implantação dos projetos educativos de cunho desenvolvimentista. Foi presidente do Instituto Nacional de Estudos e Pesquisas Educacionais Anísio Teixeira INEP $^{7}$ (1952-1964), e criou no interior deste o Centro Brasileiro de pesquisas Educacionais - CBPE e os Centros Regionais de pesquisas Educacionais - CRPE.

Inicialmente o instituto apresenta funções de natureza dúbia entre a pesquisa e a execução de princípios e propostas pedagógicas, pois, foi criado para além do desenvolvimento de pesquisas, prestar assistência técnico-pedagógica aos estados, municípios e particulares, e ainda, atuar na difusão de conhecimentos da teoria e prática pedagógica. Segundo Mendonça \& Xavier (2011), esta ambiguidade do instituto foi explorada por Anísio Teixeira, que contorna os entraves burocráticos do órgão, criando o Centro Brasileiro de Pesquisas Educacionais - CBPE em 1955, momento em que o INEP/CBPE passa a ter uma atuação central no MEC, como órgão de desenvolvimento e difusão de princípios pedagógicos, inclusive na área da educação rural.

O modelo educativo para as populações do campo, adotado no Brasil e nos demais países, visava dentro do Desenvolvimento da Comunidade, ações como semanas ruralistas, dispondo de centros de treinamentos para professores rurais, além de Clubes Agrícolas e Conselhos Comunitários. No Brasil o modelo foi denominado de extensão rural: "implementa-se no Brasil, a assistência técnica com o nome de extensão rural ou assistência técnica educativa. Esses eventos eram regulamentados pela Comissão Brasileira Americana de Educação de Populações Rurais - CBCAR (BARREIRO, 2007, p. 26). O pesquisador Sérgio Celani Leite aponta os propósitos imediatistas deste novo programa: "O objetivo imediato da Extensão Rural foi o combate à carência, à subnutrição e às doenças, bem como a ignorância e a outros fatores negativos dos grupos empobrecidos no Brasil"'(LEITE, 2002, p, 34).

Os povos rurais/do campo exerceram pressões sobre o governo para conseguir os projetos, através de lutas obtiveram algumas concessões. Como afirma Poulantzas o Estado acaba por conceder alguns direitos que surtem o efeito de amenizar os conflitos entre as classes que estão em embate, pois ele tem como objetivo organizar o espaço de acumulação do capital (POULANTZAS, 2000, p. 130). Neste período, as lutas expressam os interesses e as necessidades das instituições criados especialmente com a finalidade de defender interesses do campo: os Sindicatos Rurais e as Ligas Camponesas, que inicialmente contavam com a união do campo e cidade, ou seja, uma aliança partidária entre os camponeses de diversas regiões do país, o PCB (Partido Comunista do Brasil), tendo seu fim em 1964 com o golpe militar, sendo considerados pelos militares politizados demais. As Ligas Camponesas foram proibidas e os sindicatos rurais receberam intervenções estatais (IANNI, 2005, p. 134).

Os programas da Campanha Nacional não lograram êxito, não impediram os movimentos migratórios: "De qualquer modo, o sucesso ou não desses programas não iria impedir o grande êxodo na década de 1960"(LEITE, 2002, p.37). Almejou-se com essas inúmeras campanhas e programas governamentais no aparelho educacional, prender a população que a todo o momento tinha o desejo de possuir os mesmos atrativos concedidos ao povo da cidade. Os programas foram generalizados, não aconteceram apenas em pontos estratégicos do país.

Souza (2010) aponta que, no contexto internacional do pós-guerra, a educação rural configurou-se em uma proposta educativa articulada a um projeto de "manutenção da ordem democrática liberal, à educação para a paz e ao combate ao comunismo". No plano nacional, esse projeto representou para os segmentos modernizadores da sociedade brasileira o desafio de agrupar "uma estrutura agrária caracterizada, dentre outras coisas, pelo predomínio do latifúndio, pelo atraso tecnológico e pela alta exploração do trabalho" 
à nova dinâmica do capitalismo em desenvolvimento, desencadeando, portanto, processos de disciplinarização dos movimentos sociais do campo. Apesar das críticas iniciais ao latifúndio, o processo resultou em seu benefício, na medida em que os esteve integrada às medidas de combate aos movimentos sociais autônomos como as ligas camponesas. (SOUZA, 2010, p.4).

Como uma das pretensões deste estudo é apresentar as consonâncias nas esferas administrativas, para tal apresentamos o panorama paranaense do período.

\section{Política e econômica do Paraná pós 1930}

No Paraná, desde 1930, o interventor Manoel Ribas, procurou consolidar o Estado como próspero, destacando dos demais da federação no setor econômico. A atuação dos governantes neste período voltou-se para superar a imagem de fragilidade e dependência econômica.

Um Documento do Ipardes (2006, p. 54) afirma que no Paraná houve um discurso de modernidade no período de 1947-1982, diante de uma imagem inicial de um Estado problemático, onde imperava a violência, e a discórdia, onde "Todas as questões eram resolvidas à bala - lá como cá-" (HELLER; DUARTE, 2000, p. 33). O Estado foi palco de diversos eventos controversos como conflitos de terras, disputas políticas, acusações de corrupção, desaparecimento de pessoas.

Nas gestões (1946/1956) de Moysés Lupion não há como negar a ambiguidade dos fatos: por um lado nos discursos de Lupion, nas Mensagens para a Assembléia ${ }^{8}$, percebe-se um governador progressista, preocupado com a industrialização, buscando interligar as várias regiões do estado com sistema de rodovias e um programa efetivo de construção de escolas; nos escritos de Raul Vaz (1986) em Lupion - A verdade seu principal defensor, que o apoiou depois que seus bens foram confiscados pela ditadura de 1964, percebe-se um Lupion marginalizado, perseguido politicamente pelos opositores. Por outro lado na acusação, temos os esquerdistas, nas Mensagens de Ney Braga ${ }^{9}$, Bento Munhoz e na obra de Heller e Duarte (2000) Memórias de 64 que apresentam Lupion como corrupto tratando o Estado como um Balcão Vendas, buscando a todo instante apenas seus interesses particulares.

Porém, não conseguimos desvincular Lupion das iniciativas especificas para a população rural, principalmente medidas educacionais. Não há como negar, que no seu governo, houve um impulso desenvolvimentista, com a construção de escolas e estradas. Em Guarapuava esta preocupação é evidenciada em um jornal do município: "Em qualquer cidade ou vila, eis que se erguem prédios para escolas, eis que uma estrada rasga uma mata e corta uma campina... Aqui está a maior preocupação de nosso grande Governo-: estradas e escolas" (FOLHA DO OESTE, 26/02/1950). As escolas dariam o mínimo de instrução para essa população, e as estradas tinham a finalidade de interligar as regiões do Estado facilitando o escoamento da produção dessa mão-de-obra barata.

Verificamos a existência de acordos com a esfera federal na Mensagem do governador para a Assembleia Legislativa de 1950: "Na campanha de educação de adultos, promovida com recursos do govêrno federal [...] conseguindo instalar, em todo o Estado, quatrocentos e trinta e seis cursos, que reuniram e serviram a nada menos de 10.875 alunos" (PARANÁ, 1950, p. 320). Portanto a preocupação não vinha apenas do governo estadual, esteve em consonância com a esfera federal. Também na Mensagem de 1956, agora no segundo mandato do governador Lupion, ele afirma que: "Em 16 de junho, foi 
firmado entre o Ministério de Educação e Cultura e o Estado do Paraná mais um acordo para a construção de 16 escolas rurais e 2 grupos escolares"(PARANÁ, 1956, p. 163).

Cada mandato do Governador Lupion teve características próprias, no primeiro, a grande meta foi a colonização de Terras, nele criou-se "a Fundação Paranaense de Imigração e Colonização (1947) e o departamento Administrativo do Oeste (1948) depois transformado em Departamento de Fronteira, ligado diretamente ao Palácio do Governo" (IPARDES, 2006, p. 63-64). No segundo, fixou a população migrada do primeiro mandato, como mencionaremos adiante, por meio das medidas destinadas às populações do campo.

Como o Estado era agrícola, baseado na produção de grãos, os dois governos de Lupion incentivaram o campo paranaense, especialmente na cultura cafeeira propondo medidas de combate às pragas e prevenção da lavoura contra a geada, que prejudicava e desestimulava o agricultor, pelo rigoroso inverno do Estado.

O governo de Bento Munhoz da Rocha ${ }^{10}$ foi um divisor entre os mandatos de Lupion. Declarou que o Paraná, com a divisão de glebas do Estado feitas por Lupion, virou um balcão de vendas, conforme trecho da mensagem do Governador: "pode ser definidos sem receio de exagero [...] como de verdadeira liquidação do patrimônio territorial do Estado [...] todo se convertido aquele setor administrativo em balcão de vendas de terras" (PARANÁ, 1961, p. 61). O departamento de Colonização foi fechado por Bento, que no trecho da mensagem justifica o fechamento pela sua desorganização: “o Departamento de Terras de portas fechadas, tal a necessidade de reorganização dos serviços internos e externos, encontrados em verdadeiro tumulto" (PARANÁ, 1961, p. 61).

O Governo Munhoz, oposicionista de Lupion, propunha mudar radicalmente a forma de governo de seu antecessor centralizando suas obras na Capital. Por outro lado, o IPARDES afirma: "Bento, da mesma forma, volta-se para a questão da colonização, tendo, por meio de um programa específico coordenado pela Fundação Paranaense de Colonização e Imigração" (IPARDES, 2006, p. 63).

Apesar das críticas ao programa de colonização de Lupion, o governador Bento Munhoz, também criou mecanismos específicos para a povoação e fixação da população rural, mudando apenas o enfoque. O Departamento de Terras da administração de Lupion cedeu espaço para a Fundação Paranaense de Colonização e Imigração do governo Bento Munhoz.

Segundo a obra Paraná Reinventado organizada pelo Ipardes (2006), a principal característica do governo Bento Munhoz foi a concentração dos investimentos, obtidos pelos impostos gerados pelos trabalhadores de todas as regiões do Estado, na construção de obras na capital do Estado: "Veio Bento Munhoz da Rocha Netto e aproveitou as riquezas geradas naqueles confins para realizar grandes obras na capital, como o Teatro Guairá, a Biblioteca Pública e o centro Cívico, e para os festejos do Centenário da Emancipação Política do Paraná em 1953" (HELLER; DUARTE, 2000, p.33). Munhoz da Rocha centralizou as obras na Capital, diferenciando de Lupion que descentralizou as ações para as regiões distantes do Paraná, bem como no município de Guarapuava. Apesar de preferencialmente tender pela capital, Bento faz um esforço para atrair pessoas para as áreas rurais como a política de seu antecessor, concedendo pequenos benéficos para o interior do Estado, que se comparados a Lupion são irrelevantes.

Outra medida do Governo Bento Munhoz foi referente ao problema de escoamento da produção dessas regiões longínquas do Estado. Havia a necessidade de construção de uma rede de ferrovias e rodovias. Portanto, o setor de transporte em relação a outros, foi privilegiado por Munhoz visando: "atrair pessoas de outros estados e do estrangeiro para as zonas rurais demanda a construção de uma infra-estrutura viária capaz de atendê-las, bem 
como garantir o escoamento da produção" (IPARDES, 2006, p78). A continuação de uma política desenvolvimentista é demonstrada neste trecho, pela preocupação em criar um sistema de rodovias para o escoamento da produção para o porto de Paranaguá, objetivando diferenciada política de exportação.

O segundo mandato do Governador Lupion, iniciado em 1956, teve entre as metas, conter a população do campo na sua localidade de origem. Para isso foram dadas novas ordens para evitarem o êxodo desta população camponesa/agrícola para a cidade: "O Departamento de Geografia, Terras e Colonização recebe de Lupion, no seu segundo governo, instruções precisas de fixação do homem no campo" (IPARDES, 2006, p.86).

O Departamento de Terras, que anteriormente havia sido fechado por Bento Munhoz, foi reativado por Lupion com o objetivo de promover novos atrativos para fixar a população trazida no seu primeiro mandato. Os atrativos podem ser definidos como métodos de trabalho, e o próprio modelo diferenciado de ensino para o meio rural.

Por falta de recursos próprios para colonizar as terras, o governo incumbiu à iniciativa privada a colonização das terras devolutas do Estado. A responsabilidade pelo loteamento de terras foi dada ao capital privado, atendendo principalmente os fins políticos, com a criação das companhias colonizadoras, para a divisão de terras no Estado: "para o desenvolvimento de projetos de colonização que passariam a ser executados pelo próprio Estado (os projetos de colonização oficial) e pela iniciativa privada (os projetos de colonização empresarial privada)" (SERRA, 2010, p. 138). As Companhias de Terras agiam com predominância, nas áreas escassas de população, caso do sudoeste e norte do Estado onde ocorreram os principais conflitos por posse de terras no Paraná.

Pela precária divisão de terras das empresas da iniciativa privada, eclodiu em 1940 a Revolta de Porecatu, envolvendo posseiros e fazendeiros da região. A Guerra de Porecatu eclodiu na margem esquerda do rio Paranapanema, divisa de São Paulo com o Paraná: "Originou-se de um processo de litígios sangrentos entre os posseiros e latifundiários, que disputavam vastas áreas de novas fronteiras agrícolas do Norte do Paraná, penetradas por imigrantes gaúchos e nordestinos" (MORAIS, 2006, p. 25). A disputa ganhou destaque nacional no ano de 1950. Os grandes proprietários almejavam incorporar as terras dos pequenos que ali viviam, às suas.

Para combater os latifundiários articulou-se uma guerrilha com apoio de antigos núcleos do Partido Comunista Brasileiro (PCB) de Londrina, Apucarana, Assis, Presidente Prudente, Martinópolis, Presidente Bernardes. Os núcleos abasteciam os revoltosos com munições, armamentos e dinheiro. A guerrilha se dissolveu pelo próprio PCB, que não possuía mais condições de lutar por melhorias na região. $\mathrm{O}$ conflito de Porecatu foi uma disputa frustrada, não teve ganhador ou perdedor, em si a situação continuou da mesma maneira (SERRA, 2010, p. 138).

Dez anos depois em 1957, eclodiu o Levante dos Posseiros do Sudoeste. Esta denominação refere-se ao fato desses pequenos agricultores, estarem na região sem um documento de legalização da posse das áreas. Os posseiros entraram em litígio com as companhias colonizadoras pelas porções de terra de Chopim e Missões ${ }^{11}$. Como o governo do Estado do Paraná havia dado à iniciativa privada, a colonização das terras naquele local, estas foram vendidas às novas pessoas. Os posseiros "queriam a expulsão das colonizadoras que fomentavam o banditismo, para viver e trabalhar em paz" (HELLER; DUARTE, 2000, p. 40). Para expulsar os invasores, foi criado pelos revoltosos, um governo paralelo ao do Estado, tornando-se uma região independente para fazerem justiça por conta própria: "em setembro e outubro de 1957, em Pato Branco, Francisco Beltrão, Capanema, Dois Vizinhos e Barracão. Cerca de seis mil posseiros resolveram fazer justiça com as próprias mãos, destituindo e prendendo as autoridades" (HELLER; DUARTE, 
2000, p. 34-35). A situação de um governo paralelo é interessante e expressa a importância da organização de trabalhadores. Porém, segundo os governantes do período já explicitado, o conflito ganhou dimensão pela despreocupação do governo Lupion em acabar com a agitação, e pelo próprio governo ter interesse nas terras arrematadas na região.

Moysés Lupion para resolver a questão do Sudoeste mandou o chefe de Polícia Pinheiro Júnior, que acabou preso pelos revoltosos: "Pinheiro Júnior retornou a Curitiba, e a comissão de cidadãos continuou administrando a cidade, e decidindo tudo sem contestações" (HELLER; DUARTE, 2000, p. 36). Percebemos uma estratégia nesta disputa, pois o chefe de polícia, em poucos dias foi libertado e pode voltar para a Capital para relatar o ocorrido para o Governo do Estado. Por outro lado o governo paralelo ao do Estado continuou existindo, demorando alguns meses até sua dissolução.

O conflito foi solucionado por Ney Braga em 1962, que recebeu o presidente da república João Goulart. Para solucionar o conflito foi feito um depósito como indenização aos colonos, deixando as terras para os posseiros. Resolvido o conflito no Sudoeste do Estado, promoveram uma discussão na Assembleia Legislativa paranaense por causa de uma lei que determinava consenso dos legisladores na desapropriação de terras em qualquer região do Estado.

Com a incidência de conflitos em todos os cantos do Paraná, os recursos destinados à educação tiveram papel fundamental na administração estadual, como forma de apaziguar a população exaltada a não promover revoltas durante os mandatos de Lupion.

O governo Lupíon criou programas específicos para atender as deficiências do ensino e as demandas da população dos locais mais longínquos do Estado, como a criação de 500 escolas primárias através de convênios com as prefeituras do interior, e solicitações de construção e manutenção de escolas próprias (IPARDES, 2006, p. 88). Com isso percebemos a consonância da política não apenas do governo federal e do estadual, mas também das prefeituras como poder local. É importante frisar que o termo, prefeituras do interior, demonstra a construção de escolas longe do eixo Curitiba-Paranaguá.

Além dessas medidas, foram criados cursos para formação de professores ${ }^{12}$. Lupion primou em descentralizar a formação de professores da Capital, para que se formassem mais profissionais em pouco tempo:

Precisamos formar o mestre de cada região em sua própria região (sic!) - redução da evasão escolar, fundação de Associação de Amigos das Escolas, criação de Cursos Normais regionais e das "Missões Culturais", já referidas, que visam [...] destruir a ignorância (IPARDES, 2006, p. 88).

O Paraná deveria passar de um Estado essencialmente agrícola para industrial, buscava aumentar suas exportações e promover a instalação de indústrias. Moysés Wille Lupion de Tróia, contou com a ajuda de um grande número de colaboradores, dentre eles Erasmo Pilotto, secretário de governo nos dois mandatos, que comandou os programas de expansão educacional para a área rural no Estado.

Miguel (1997) reconhece no período (1938-1946), quando foram criados no Estado do Paraná os cursos de formação de professores e foi proposta a criação da Escola Normal Rural Feminina, a compreensão por parte do governo Manoel Ribas de que a educação deveria formar para o trabalho, proporcionando um mínimo de conhecimentos (Código de Educação de 1937 apud, Miguel, 1997, p. 60-70), a responsabilização da educação pela redução do êxodo rural, atribuindo ao professor a responsabilidade pelas mudanças sociais, incumbido da tarefa de cultivar nas populações do campo, o gosto pela vida do campo. 
Entretanto, segundo esta autora, no governo Moyses Lupion, nas suas duas gestões a partir de 1947, no Paraná, que ocorreu uma grande expansão dessas escolas, quantitativa e qualitativamente. Para Miguel (1997, p. 100), o pensamento de Erasmos Pilotto, que influenciou a organização da Escola de Professores de Curitiba, e que terá papel de destaque nas reformas educativas do Estado do Paraná a partir de 1948 (Duas gestões do Governo Lupion 1947-1950, 1955-1960), recebe influência da Pedagogia da Escola Nova, num período de avanços desta teoria, quando supera algumas das suas antinomias (secundarização do papel do professor na relação ensino-aprendizagem com a hipervalorização do aluno e a o desprezo pela cultura humana e pelos conhecimentos científicos, quando da ênfase na pesquisa e atividade dos alunos), com a contribuição do pensamento de Wallon, que segundo esta autora resgata o papel social da escola como de transmissora do saber e do professor como "organizador da relação educativa professoraluno". Portanto a autora identifica neste pensamento e, na formação da Escola Normal de Curitiba, um novo pressuposto da relação escola-trabalho, para a época, não de formação para as atividades agrícolas, de "instrumentalização educacional do trabalhador, mas também da maior participação da cultura" (p. 105).

Também foi criada neste período, a Lei Orgânica do Ensino Normal, orientada por Pilotto com o objetivo da reversão da política de formação de professores para as escolas rurais, até então instituída, em que as escolas normais localizadas nos centros urbanos formavam professoras para estes locais, enquanto que, as que atuavam no meio rural não tinham formação específica. São criados Cursos Normais Regionais para deslocar a formação de professoras para o interior, que formariam professoras para atuarem no próprio local de formação. As instruções e programas criados para estes cursos apresentam finalidades de aprofundar os conhecimentos acerca dos problemas locais, da cultura pedagógica e das formações técnica e científica, portanto, sem o caráter exclusivo de transmissão de técnicas produtivas, articulando, portanto dois aspectos o da "melhoria das formas de vida" e a "elevação cultural da população" " (Miguel, 1997, p. 151-153).

Para isto foram criadas as Missões Culturais, inspiradas na experiência mexicana, em que os jovens professores deslocavam-se para o interior, trabalhando temporariamente na formação de futuros professores e abrindo novas escolas. Para Pilotto esses professores deveriam "atuar como mentores e líderes sociais desinteressados de pequenas comunidades, e cujos objetivos acessórios [eram]: procurar o melhoramento cultural e profissional dos mestres rurais e integrar a gente adulta da comunidade no progresso cultural médio desejável da nação". (PILOTTO,1959. p.57 apud De Boni, 2007, p.6)

Contraditoriamente ao indicado por Miguel (1997), De Boni (2007) assinala as críticas recebidas por Pilotto, em função da definição de que estas escolas não exigiriam o ginasial, ou seja, instituíram escolas de formação de professores para atuar em escolas rurais que podiam ser cursadas por egressos do curso primário.

Em suma, percebemos características comuns entre os governantes mencionados: todos pensavam em um progresso, o desenvolvimentismo. Não se tem como negar que houve o surto de progresso no período. O crescimento populacional foi considerável: "A população paranaense cresceu de 1.236.000 habitantes em 1940, para 2.129.000 em 1950, e para 4.200.000 em 1960 [...] quase três vezes maior que a do Brasil, que é de 2,7\% (PARANÁ, 1961, p. 4).

Dentre os municípios do estado Guarapuava foi uma das regiões longínquas para onde vários recursos foram destinados. Quando mencionamos Educação Rural não há como esquecer Guarapuava. Para compreendermos como foi esse processo no município, torna-se pertinente constatarmos de como ele estava imerso nessa estrutura. Quais eram 
seus aspectos políticos e econômicos? Analisamos pelo viés político e econômico para alcançarmos nosso objeto de Estudo, o aparelho educacional.

\section{A Guarapuava Rural}

O cenário guarapuavano no período estudado é marcado por ser um dos maiores municípios do Estado, totalmente baseado na agricultura e nas atividades da área rural: no troperismo, e extração de erva mate e madeira, como atividade econômica até 1950. Tornase necessário retornarmos aos anos de 1930, em que a Revolução varguista influenciou a cidade de Guarapuava por sua grande extensão territorial e por ramificar-se em boa parte do centro e oeste do Estado.

A Revolução de 1930 influenciou a cidade de Guarapuava no aspecto político e econômico: Affonso Alves de Camargo foi governador do Paraná nos anos de 1916 e 1928, no seu segundo mandato foi deposto pela ditadura de Vargas. Com o golpe de Vargas, foi nomeado em 1932, o interventor Manoel Ribas para chefe do Estado. Tão logo Manoel Ribas assumiu "Um dos primeiros atos do novo interventor foi destituir o prefeito de Guarapuava [...] Augusto Gomes de Oliveira. Em seu Lugar assumiu [o professor] Arlindo Martins Ribeiro interventor até março de 1936" (POHL DA SILVA, 2010, p.71). Possuir aliado na região significaria um grande elo com o Sul e os países vizinhos.

A historiadora Pohl da Silva (2010) em sua obra que trata da arte da política refaz através do Jornal Folha do Oeste, fundado em 1937, a caminhada política do guarapuavano Antonio Lustosa de Oliveira, mencionando o influente político, amigo de Moysés Lupion. A autora projeta em sua discussão a popularidade do jornal na década de 1930 em que a cidade era: "Uma pequena cidade interiorana, castigada pelo difícil acesso geográfico, isolada de outros centros, com escassos recursos de transportes e comunicações, na qual a população rural sobrepujava de longe a população urbana" (POHL DA SILVA, 2010, p. 76). A população encontrava-se retirada dos grandes investimentos e com dificuldade de comunicação com as demais regiões do Estado, devido a problemas com estradas. O Jornal Folha do Oeste foi um dos mais importantes da cidade, tendo sua circulação estendida por mais de quarenta anos. Por meio dele se pode em escala reduzida analisar de que forma ocorreram os grandes acontecimentos do período abrangido por sua publicação. Conseguimos pontuar fatos importantes da Educação Rural no local de inserção de Guarapuava.

Guarapuava também é objeto de estudo da geógrafa Márcia da Silva (2007) que apresenta as condições da população guarapuavana, demonstrando a política em consonância com a esfera federal e estadual. De acordo com a mesma, tornou-se importante reorganizar o território, voltando-se para o rural, sendo os imigrantes fundamentais para o processo. Tanto que o município recebeu tardiamente em 1951 uma leva de imigrantes, composta de 500 famílias descendentes de alemães, iugoslavos, romenos, húngaros denominados de Suábios. Além disso, ainda em Guarapuava, nos anos que se seguiam a 1951 recebeu uma migração interna vinda do Norte do Paraná, do Rio Grande do Sul e Santa Catarina atraída pelas políticas dos governos municipais.

A bibliografia sobre o tema, salienta que Guarapuava teve aumentos e retrocessos populacionais. $\mathrm{O}$ aumento foi consequência da forte campanha de imigração e migração que fazia do Paraná, a capital do progresso, e a região de Guarapuava uma terra de oportunidades em função do despovoamento. Os retrocessos se deram pelos inúmeros desmembramentos, ou seja, pela criação de novos municípios, haja vista grande parte dos atuais municípios da Região oeste, sudoeste, e central terem sido territórios pertencentes a 
Guarapuava. Sendo as últimas divisões territoriais as da Campina do Simão, Candói e Foz do Jordão ocorridas na década de 1991 à 2000 (SILVA, 2007, p. 76).

A Segunda Guerra Mundial também foi sentda em Guarapuava. O conflito armado trouxe prejuízos para a cidade: "A Segunda Guerra Mundial (1939-1945) provoca dificuldades para a obtenção de alimentos, e a arregimentação de soldados da região, para participar nos combates, traz inseguranças e incertezas junto a população" (FERNANDES, 2010 , p. 64). Os alimentos que chegavam a cidade eram racionados, em meio ao constante medo da guerra avançar para o continente americano. $O$ fértil imaginário da população receava que o Brasil fosse palco de conflitos. Guarapuava enviou militares para a Força Expedicionária Brasileira para os combates na Itália e Alemanha quase derrotada. Podemos perceber as influencias do Continente europeu, sendo sentida nas regiões mais longínquas do país, neste caso Guarapuava.

A atividade madeireira em Guarapuava foi intensa no período analisado. É importante frisar que na Segunda Guerra Mundial houve preocupação com a importação de locomotivas e vagões para o transporte da madeira, pois não se tinha um fornecedor fixo, condição que gerou intenso trabalho da classe empresarial, de Ponta Grossa ao Porto de Paranaguá (FERNANDES, 2010, p. 66).

A estrada de ferro na região central do Paraná chegou a Guarapuava em 1954, levando Guarapuava transportar para Ponta Grossa a madeira extraída: "Por meio de carroças, essa madeira era transportada ao município de Ponta Grossa, que era entroncamento da Rede Viação Paraná- Santa Catarina, onde o produto era embarcado com destino a diversos locais" (POHL DA SILVA, 2010, p. 98). A atividade madeireira nos primeiros anos foi difícil de ser exercida em Guarapuava que possuía vasta área para desmatamento, porém não tinha beneficiamento na região, sendo necessário o seu transporte para empresas beneficiadoras de Ponta Grossa.

A historiadora Márcia Tembil (2007) aponta as nuances de uma Guarapuava desenvolvimentista, voltada para o progresso. A autora confirma sua tese baseada nos aspectos arquitetônicos, os contrastes de uma sociedade guarapuavana, com uma herança colonial (agrícola), com a tendência de acompanhar os grandes centros em busca da modernidade. Construído para a finalidade, a partir da década de 1950, ruas, mercados, lojas; o velho convivendo com o novo e a predominância deste segundo.

Estes são alguns dos aspectos políticos e econômicos do Município de Guarapuava quando Moysés Lupion foi Governador do Paraná. O município de Guarapuava foi voltado para a área rural, baseado em agricultura de subsistência trazida pelos processos de imigração e pela extração de madeira principal atividade econômica na região. Com base nisso, apontamos que o aparelho ideológico estatal educacional foi também voltado para o rural. A Educação Rural tomou forma em Guarapuava, e os principais investimentos para esta modalidade de ensino vieram para a região.

No próximo tópico deste trabalho após apresentarmos esse resumido cenário guarapuavano, apontaremos com base no Jornal Folha do Oeste, de que forma se constituiu a educação e a expansão dessa modalidade educacional rural na cidade de Guarapuava. Consideramos Guarapuava como uma cidade rural, sua educação voltada para a modalidade de ensino rural/campo.

\section{A Educação Rural em Guarapuava}

O Jornal Folha do Oeste apresentou em 1950 o discurso do Partido Socialista Democrático (PSD), em que Lustosa, do mesmo partido político de Lupion, elogiou o correligionário: "E isso em nosso Estado se deve ao Sr. Lupion, é preciso que o não 
esqueça o povo e principalmente não esqueça, que este notável estadista surgiu nas fileiras da pujante P.S.D"(FOLHA DO OESTE, 15/01/1950). O discurso predominante no Jornal Folha do Oeste é do Partido Socialista Democrático. A fala do governador Moysés Lupion leva a crer na existência de uma proximidade entre o fundador do jornal Antonio Lustosa de Oliveira e o Governador do Paraná.

O jornal divulgava apenas os benefícios trazidos pela administração estadual. Retornamos a concepção de Poulantzas para afirmar o Jornal como discurso do Estado, sendo: "o Estado não [...] um bloco monolítico, mas um campo estratégico" (POULANTZAS, 2000, p. 141). Este campo estratégico que tem como missão levar uma ideologia para a população acreditar firmemente.

No caso do Paraná, especificamente no município de Guarapuava foi apresentada a política Res non verba ${ }^{13}$, não funcionava da maneira descrita pelo jornal. O Jornal Folha do Oeste utilizava deste termo para explicar as ações do Governo de Moysés Lupion como construção de escolas e estradas. Entretanto, percebe-se que algumas escolas podem ter sido inauguradas sem a intenção de sua utilização. Por isso, não se funcionava na prática o pregado no discurso. Como esclarece Poulantzas sobre ideologia: "A ideologia, dominante, que o Estado reproduz e inculca, tem igualmente por função constituir o cimento interno dos aparelhos de Estado e da unidade de seu pessoal" (POULANTZAS, 2000, p.156).

O Estado finge uma ideologia neutra objetivando interesses específicos: "Esta ideologia é precisamente a do Estado neutro, representante da vontade e do interesse gerais, árbitro entre as classes em luta." (POULANTZAS, 2000, p. 128-129). O Estado não é apenas um mediador de classes, porque ele possui um esqueleto especifico, além de mediar promove ações entre as classes e frações destas.

Os pesquisadores Amaral e Herold Jr (2010) também afirmam que escolheram os jornais como fontes de pesquisa porque foi através deles que se conseguiu verificar cotidianamente a educação como um assunto de destaque no período de 1930 a 1960 permeando embates políticos locais nos processos modernizadores da economia e sociedade de Guarapuava. Os autores apresentaram uma Guarapuava em que os acordos políticos e econômicos estiveram sempre pautados em um desenvolvimento educacional.

O termo Res non verba comumente aparece para demonstrar os discursos da administração estadual. A expressão se configurou pela eficácia do governo Lupion: "Res non verba' - ato e não palavra, eis o lema que se adapta perfeitamente à atuação eficientíssima de nosso grande governador" (FOLHA DO OESTE, 12/05/1949). O Termo aparece também em outras edições enaltecendo a figura do governador para designar que ele sem duvida alguma faz e não apenas fala: "O nosso Governador não é homem de simples palavras, não é homem impatriota, mas o homem do "res no verba" e isto nos prova e provará a todos aqueles que duvidarem destas informações"(FOLHA DO OESTE, 19/03/1950).

O Jornal a Folha do Oeste de Junho de 1949, o mesmo em que retratamos acima a expressão que marca seus mandatos, enfatiza a existência na cidade de algumas construções em andamento e outras quase concluídas. Entre as futuras construções a criação de uma escola de Educação Rural, além de grupos escolares com outras denominações e a construção de postos de saúde. A característica de seus mandatos, como já mencionado, foi a descentralização das obras da capital do estado. Os governadores Bento Munhoz e Ney Braga questionaram se as obras realmente existiram. Nos jornais pesquisados não encontramos nenhuma menção a inauguração desta ou aquela escola no período mencionado. Somos direcionados a um novo questionamento os discursos de Ney Braga mencionados anteriormente estão corretos? 
O Jornal ainda enfatizou cursos de formação de professores. Parabenizando os guarapuavanos com uma escola normal secundária no mesmo ano de 1949, como presente para a população:

A Escola Normal Secundária é um valiosíssimo presente que ganha o povo de Guarapuava, como reconhecimento ao seu valor e atendendo às suas necessidades, pois vem preencher uma grande lacuna que é a de facilitar o ensino de professores no interior, oferecendo oportunidades aqueles que não podem sair daqui e que, assim, veem a possiblidade da realização de um justo sonhos de moços (sic) - ser Professor. (FOLHA DO OESTE, 13/03/1949).

A escola apesar de citada como uma necessidade é colocada com benesse do estado, não como direito do povo ou dever do estado. Os direitos dos trabalhadores apesar da necessidade não são reconhecidos como deveres pelo Estado, mas mencionados como bondade: "Em relação principalmente às classes dominantes [...] o Estado [...] organiza o interesse político a longo prazo do bloco no poder, composto de várias frações de classe burguesas" (POULANTZAS, 2000, p. 128-129). O Estado na construção de escolas tem como objetivo, trazer pequenas benfeitorias para mostrar aproximação das classes populares, divulgando o fato como grandioso para atender favores específicos da classe dominante. Cuidar da população carente foi a regra, apesar do abismo entre teoria e prática: "Sempre existe uma distância estrutural entre a teoria e a prática, entre a teoria e o real" (POULANTZAS, 2000, p. 20-21). A citação de Poulantzas (2000) remete a grande dificuldade de cumprir o que é discursado.

A escola de formação de professores foi apontada por Pohl da Silva (2010) como projeto e reivindicação do deputado Antonio Lustosa de Oliveira um ano antes de tornar-se noticia no Folha do Oeste como uma dádiva, um presente ao povo: "Lustosa apresentou, em $1^{\circ}$ de outubro de 1948, o projeto de lei de criação da Escola Normal de Guarapuava" (POHL DA SILVA, 2010, p. 37). O projeto do político pautava-se pelo município possuir mais de 80 mil habitantes, apesar da maioria viver na sua área rural, tornava-se necessária uma Escola Normal Secundária para dar conta da existência da demanda da Escola Normal Regional Primária. A Secundária deveria atender a formação de professores para os locais mais longínquos do município e seus inúmeros distritos.

O jornal trouxe a noticia dessa primeira Escola Normal Regional Primária administrada pelas Irmãs Severas do Espírito Santo no ano de 1946, com a quantidade de recursos mandados pelo governo estadual para seu funcionamento: "o Governo do estado assinou decreto a 14 do corrente, concedendo ao Colégio Nossa Senhora do Belém, desta cidade, a importância de Cr\$100.000,00, como auxilio a Escola Normal Regional, mantida por aquele colégio" (FOLHA DO OESTE, 26/05/1949). Torna-se importante destacar que foram duas escolas criadas para a formação de professoras. A Escola Normal Primária para as séries iniciais, não se sabe ao certo quando foi criada e a reivindicada por Antonio Lustosa denominada de Escola Normal Secundária, devido a existência da primeira e pela grande quantidade de habitantes.

Percebemos nos jornais analisados o papel fundamental da escola na construção dos discursos. Reforça nossa problemática inicial de expansão de escolas na modalidade de ensino rural, com ressalvas pela demonstração que algumas não foram efetivamente construídas e outras foram obras inacabadas. Porque o Jornal Folha do Oeste nos remete a concepção de ser um apêndice do Estado, prolongamento que reproduz o seu discurso na cidade de Guarapuava. 

Considerações finais

A Educação rural independente do local de fixação, seja na administração federal, estadual ou municipal, surgiu como uma necessidade. Fato relevante para percebemos como se configurou este processo. Necessidade essa também pertinente aos nos dias de hoje com a emergência e a consolidação de novos mecanismos para o campo brasileiro como a modalidade de ensino: Educação do Campo.

Para tanto é importante apontar que "Não existe nem sucessão, nem conexões, nem acontecimentos. É o tempo presente que atribui seu sentido ao antes e ao depois [...] o passado se reproduz sempre no presente que não é mais que seu eco" (POULANTZAS, 2000, p. 108). Os acontecimentos e os fatos seguintes são importantes, porém só fazem sentido quando pretendemos responder perguntas atuais. Perguntas que clamam na nossa problemática para consolidar a Educação do Campo.

O projeto para a área rural emergiu com recursos do capital estrangeiro baseado em convênios com os Estados Unidos. Ao inserirmos o Estado do Paraná na discussão das medidas governamentais para a população do campo evidencia-se uma intensiva preocupação nos mandatos dos governadores desenvolvimentistas, em especial com Moysés Lupion. Os mandatos de Lupion como governador do Estado demonstraram a pertinência de uma política intensiva de migração/ imigração para o Paraná e posterior fixação destas populações, sendo a educação mecanismo fundamental. A importância de Guarapuava no processo é notória pela sua economia pautar-se no agrícola, sendo uma cidade com grande extensão territorial e com áreas despovoadas, ramificando-se em vários municípios paranaenses.

Considerando, segundo Poulantzas: "o Estado, como é o caso de todo dispositivo de poder, é a condensação material de uma relação" (POULANTZAS, 2000, p. 106). Entendemos que a luta dentro de seus aparelhos desiguais: "Ela resulta também de sua estrutura de condensação de uma relação de forças, logo do lugar preponderante em seu seio da classe ou fração hegemônica sobre as outras classes e frações do bloco no poder" (POULANTZAS, 2000, p. 139). A burguesia nesta disputa é quem tem em seu poderio os aparelhos mais importantes.

Em Guarapuava o discurso Burguês foi representado pela benfeitoria trazida pela Escola Normal Primária Secundária. O Jornal Folha do Oeste traz como agrado para toda a população, mas poderia se tornar professora mesmo nos locais mais longínquos do Estado apenas a classe mais abastada da região, a população mais pobre não poderia dar-se ao prazer de lecionar: "Todos são livres e iguais diante da lei sob a condição de que todos sejam e tornem-se burgueses, o que a lei ao mesmo tempo permite e interdita" (POULANTZAS, 2000, p. 89) Poulantzas pode ser entendido nesta premissa quando apresenta a igualdade entre as pessoas com a finalidade de serem burguesas. Somos iguais quando pertencemos a uma burguesia. Todo processo de escolha se tem uma exclusão dos que não são tão iguais. Escolher ser professor foi para poucos. O Colégio Belém foi uma escola destinada ao ensino particular apesar de receber auxílio estadual para a formação de professores.

Além disso, as relações entre as classes: dominante e dominada, e as frações destas que compõem qualquer Estado e tantas outras subdivisões, não ocorrem da mesma forma. O partido de esquerda, no caso brasileiro o PCB, esteve em evidência no pós-guerra, porém não significa o poder de aparelho ou de todo o Estado. O Estado tem a capacidade de absorver os conflitos ocasionados pela diversidade das classes que o compõem, e muitas vezes de aproximar-se das forças que detém o poder econômico, no caso a elite à frente dos aparelhos. 
Muitos conflitos ainda ocorrerão por melhores condições dentro de seus aparelhos, seja para evitar revoltas e o bem de todos dentro do Estado, ele concede através das lutas populares pequenos presentes as classes dominadas, numa forma de apaziguar a relação tensa entre o campo e a cidade. Em uma discussão ampla podemos apresentar esta relação em outros sistemas políticos: "mesmo o fascismo foi obrigado a tomar uma série de medidas positivas para as massas (reabsorção do desemprego, manutenção e às vezes melhoria do poder real de compra de certas categorias populares, legislação dita social), o que não exclui, bem ao contrário, o aumento na exploração das massas" (POULANTZAS, 2000, p. 30).

Pressupostos não apenas explicitado com países desenvolvidos da Europa, mas com países subdesenvolvidos como o Brasil. Os segundos, mesmo dentro de sistemas intitulados democráticos, possuem maior preocupação em controlar a população, podendo ou não utilizar a força de repressão do Estado. A repressão não é utilizada porque é necessário aparentar uma situação de tranquilidade para atrair novos investimentos em consonância com as várias esferas componentes do Estado, ou seja, convênios internos e externos.

\section{Referências}

AMARAL, Mari Lucia do; HEROLD JUNIOR, Carlos. Representações sobre a relação entre educação e modernização em Guarapuava entre 1930 e 1960. Revista Histedbr Online, Campinas, n. 38, p.36-48, jun. 2010. Disponível em: $\langle$ http://www.histedbr.fae.unicamp.br/revista/edicoes/38/art04_38.pdf $>$. Acesso em: 17 fev. 2012.

AMMANN, Safira Bezerra. Ideologia do Desenvolvimento de Comunidade no Brasil. São Paulo: Cortez, 1997.

BARREIRO, Edson. Políticas Educacionais e escolas rurais no Paraná 1930-2005. Maringá: UEM, 2007. 107p. Dissertação (mestrado em Educação). Universidade Estadual de Maringá.

BARREIRO, Iraide Marques de Freitas. Educação rural capitalista: a contradição entre a educação modernizadora e a educação de classe popular na Campanha Nacional de Educação Rural. Campinas: UNICAMP, 1989. 293p. Dissertação (mestrado em Educação). Universidade Estadual de Campinas.

BEZERRA NETO, Luiz \& SANTOS BEZERRA, Maria Cristina. A importância do materialismo histórico na formação do Educador do campo. Revista HISTEDBR On-line, Campinas, número especial, p.251-272, ago.2010.

BIELSHOWSKI, Ricardo. Pensamento econômico brasileiro: o ciclo ideológico do desenvolvimentismo. Rio de Janeiro: Contraponto, 2004.

BLOCH, Marc. Apologia da História ou o ofício do Historiador. Rio de Janeiro: Jorge Zahar, 2001.

CALDART, Roseli Salete. Educação do campo: notas para uma análise de percurso. Trab. Educação Saúde. Rio de Janeiro, v.7. n.1, p. 35-64, mar./jun.2009. 
CARONE, Edgard. A República Liberal II: evolução política (1945-1964). Difel, 1985.

CPDOC. Centro de Pesquisa e Documentação de História Contemporânea do Brasil. Educação Rural, Mesa Redonda. Rio de Janeiro: Fundação Getúlio Vargas, 1951. Documento Mimeo.

DE BONI, Maria Ignês Mancini. Erasmo Pilotto e as Escolas Normais Regionais no Paraná. Universidade Tecnológica do Paraná, 2007. Disponível em 〈http://www.utp.br/cadernos_de_pesquisa/pdfs/cad_pesq4/13_erasmo_pilotto_cp4.pdf.> Acesso em 21 de out. 2013.

FOLHA DO OESTE. 26 de Junho de 1946.

FOLHA DO OESTE. 13 de Março de 1949.

FOLHA DO OESTE. 12 de junho de 1949.

FOLHA DO OESTE. 15 de Janeiro de 1950.

FOLHA DO OESTE. 26 de fevereiro de 1950.

FURTADO, Celso. O Capitalismo Global. São Paulo: Paz e Terra, 1998.

HELLER, Milton Ivan; DUARTE, Maria de Los Angeles González. Memórias de 1964 no Paraná. Curitiba: Imprensa Oficial, 2000.

HUXLEY, Julien. Carta a Anísio Teixeira, Nova Iorque, 12 jun. 1946. Carta publicada em VIANA FILHO, Luís. Anísio Teixeira: a polêmica da educação. Rio de Janeiro: Nova Fronteira, 1990. p. 105-106. Disponível em: <http://www.bvanisioteixeira.ufba.br/cartas/huxley.htm>. Acesso: 25 Nov. 2011.

IANNI, Octavio. 4. A formação do proletariado rural no Brasil - 1971. In: STEDILE, João Pedro (org.). A Questão agrária no Brasil: O debate na esquerda- 1960-1980. Expressão Popular. São Paulo: 2005.

INSTITUTO PARANAENSE DE DESENVOLVIMENTO - IPARDES. O Paraná reinventado: política e governo. 2 ed. IPARDES, Curitiba, 2006.

LEITE, Sérgio Celani. Escola Rural: urbanização e políticas educacionais. Editora Cortez. São Paulo: 2002.

MENDONÇA, Ana W; XAVIER, Libânia. INEP no contexto das políticas do MEC (1950/1960). Disoponível em: <http://www.educacao.ufrj.br/artigos/n1/numero1artigo6.pdf>. Acesso 28 nov. 2011.

MIGUEL, Maria Elisabeth Blanck. A Formação do Professor e a Organização Social do Trabalho. Curitiba: ED. da UFPR, 1997. 
MORAIS, Clodomir Santos de. I- História das Ligas Camponesas do Brasil -1969.In: STEDILE, João Pedro (org.). A Questão agrária no Brasil: História e natureza das Ligas Camponesas 1954-1964. Expressão Popular. São Paulo: 2006.

OLIVEIRA, Francisco. Crítica à razão dualista: o ornitorrinco. São Paulo: Boitempo, 2003.

PAIVA, Vanilda. História da educação popular do Brasil: educação popular e educação de adultos. São Paulo: Loyola, 2003.

PARANA. Mensagem apresentada à Assembléia Legislativa do Estado por ocasião da abertura da Sessão Ordinária de 1950 pelo Senhor Moysés Lupion, Governador do Paraná. Curitiba, 1950. Disponível em: http://www.arquivopublico.pr.gov.br/arquivos/File/pdf/Ano_1950_MFN_942.pdf> Acessado em $13 \mathrm{dez} 2011$.

Mensagem apresentada à Assembléia Legislativa do Estado por ocasião da abertura da $1^{\mathrm{a}}$. Sessão Ordinária da $2^{\mathrm{a}}$. Legislatura pelo Senhor Bento Munhoz, Governador do Paraná, em 01/05/1951. Disponível em : < http://www.arquivopublico.pr.gov.br/arquivos/File/pdf/Ano_1951_MFN_944.pdf >

Acessado em: 11 jan 2012.

Mensagem apresentada à Assembléia Legislativa do Estado por ocasião da abertura da $1^{\text {a }}$. Sessão Legislativa Ordinária de 1956 pelo Senhor Moysés Lupion, Governador do Paraná. Disponível em: http://www.arquivopublico.pr.gov.br/arquivos/File/pdf/Ano_1956_MFN_945.pdf> Acessado em $13 \mathrm{dez} 2011$.

Mensagem apresentada a Assembléia Legislativa do Estado por ocasião da abertura da $3^{\mathrm{a}}$. Sessão Ordinária da $4^{\mathrm{a}}$. Legislatura pelo Senhor Ney Aminthas de Barros Braga, Governador do Estado, em 01/05/1961. Disponível em: < http://www.arquivopublico.pr.gov.br/arquivos/File/pdf/Mensagem_1961_Governo_MFN 1663.pdf> Acessado em $13 \mathrm{dez} 2011$.

POHL DA SILVA, Walderez. De Lustosa a João do Planalto: A Arte Política na Cidade de Guarapuava (1930- 1970). Guarapuava: Editora Unicentro, 2010

POULANTZAS, Nicos. O Estado, o poder, o socialismo. São Paulo: Paz e Terra, 2000.

RIBEIRO, Marlene. Educação popular: um projeto coletivo dos movimentos sociais populares. Perspectiva, Florianópolis, v. 26, n. 1, 41-67, jan./jun. 2008.

RODRIGUES, Neidson. Estado, Educação e Desenvolvimento Econômico. Editora Cortez. São Paulo: 1987.

SAVIANI, Dermeval. História das Idéias Pedagógicas no Brasil. Campinas, SP: Autores Associados, 2007. 
SERRA, Elpídio. A posse da Terra e os Conflitos Rurais no Paraná. In: SAQUET, Aurélio; SANTOS, Roseli Alves dos (org.). Geografia agrária, território e desenvolvimento. Expressão Popular. São Paulo: 2010.

SILVA, Márcia da. Análise política do território: poder e desenvolvimento no CentroSul do Paraná. Guarapuava: Unicentro, 2007

SOUZA, Claudia de Moraes. Discursos intolerantes: o lugar da política na educação rural e a representação do camponês analfabeto. Disponível em: $<$ http://www.historica.arquivoestado.sp.gov.br/materias/.../rural.pdf $>$. Acesso: 10 nov. 2010.

TEMBIL, Márcia. Em busca da cidade moderna: Guarapuava... recompondo histórias, tecendo memórias. Guarapuava: Unicentro, 2007.

UNIÃO PANAMERICANA. Documento do Seminário Regional de Educación en la América Latina. Departamento de Assuntos Culturales da Unión Paranamericana: Caracas, 1949.

VAZ, Raul. Moysés Lupion: a verdade. Curitiba: Paratodos, 1986.

\footnotetext{
${ }^{1}$ Mestrando em História pela Universidade Estadual do Centro-Oeste- UNICENTRO. Bolsista da Coordenação de Pessoal de Nível Superior, Capes, digao_santos9@ @otmail.com.

${ }^{2}$ Doutora em Administração e Políticas Públicas pela UNESP e Docente do Mestrado em Educação da Universidade Estadual do Centro-Oeste- UNICENTRO, angelamhidalgo@ gmail.com.
}

\begin{abstract}
${ }^{3}$ A concepção de Estado pauta-se em Nicos Poulantzas (2000). Os termos aparelhos e aparatos remetem ao Estado concebido como condensação de forças entre frações de classes, materializados nos seus vários aparelhos. O autor apresenta os aparelhos: sociedade civil, educação, igreja, família, entre outros como componentes do Estado com discursos heterogêneos absorvidos como únicos.Não podemos conceber o Estado como um simples mediador da classe operária e burguesa. Porque não existem apenas essas duas classes, possuímos frações de classes: como as ligas camponesas, os sindicatos rurais e os próprios trabalhadores rurais. Esta população anseia por demandas especificas dentro do Estado e a educação voltada para o meio rural torna-se uma destas demandas. O Estado do Paraná com as demandas especificas implementadas pelo governo Lupion, como veremos a seguir, tiveram como missão apaziguar a população rural. Conceder pequenos atrativos, medidas governamentais, para conter a população revoltosa que clamavam por melhores condições de vida. O discurso do Estado apesar de não possuir uma pretensão especifica inferiorizou a população do campo. Segundo Poulantzas (2000) o embate entre as frações de classe é desigual entre estes vários componentes do estado, sendo absorvida pela elite dominante, mesmo que a esquerda consiga o poder, a direita não deixará esta de controlar os aparelhos importantes do Estado, como o educacional.
\end{abstract}

${ }^{4}$ Estudo de Amaral e Herold Jr (2010) sobre a educação na cidade de Guarapuava demonstra como se desenvolveu a Educação no município, no período de 1930 a 1960.

${ }^{5}$ Considera-se Guerra Fria o período de 1945 à 1991. Período em que predominava no globo duas ideologias: a Socialista encabeçada pela União Soviética e a capitalista pelos E.U.A. Bipolaridade que se extinguirá em 1991 com a desintegração da União Soviética. 
${ }^{6}$ Josué de Castro, após a publicação do livro a "Geografia da Fome", em 1946, e da participação em 1948, como delegado na Primeira Conferência Latino-Americana de Nutrição, em Montevidéu, promovida pela FAO, Órgão das Nações Unidas para Agricultura e Alimentação, transforma-se em um dos intelectuais brasileiros mais atuante e com projeção internacional nas questões relacionadas à nutrição. Na ocasião é escolhido como membro do Comitê Consultivo Permanente de Nutrição deste órgão. Em 1950, Josué organiza a Segunda Conferência Latino-Americana de Nutrição da FAO em Petrópolis, no Estado do Rio de Janeiro. Entre 1952 e 1956 foi Presidente do Conselho Executivo da FAO, sediado em Roma. Dentre suas principais realizações neste período, destacam-se a promoção da Terceira Conferência Latino-Americana de Nutrição, em 1953, na Venezuela e a idealização de uma "reserva internacional contra a fome" para ajudar países em situação emergencial. http://www.juraemprosaeverso.com.br/Biografias/JosuedeCastro.htm acesso em 21 fev 2012.

${ }^{7}$ O Instituto Nacional de Estudos Pedagógicos - INEP criado em 1937, foi dirigido por Lourenço Filho de 1938 até 1945, quando foi substituído por Murilo Braga entre 1945 e 1952 e, com a morte deste, Anísio Teixeira assume a administração ente 1952 e 1964.

${ }^{8}$ As mensagens para a Assembleia eram relatórios encaminhados para os deputados anualmente para apresentar a situação dos departamentos e secretárias do Estado. Apesar desse intuito muitas vezes eram utilizados para desprezar o trabalho dos governadores anteriores.

9 Governador Ney de Barros Braga, sucessor de Lupion, foi eleito para 1961 com um discurso criticando as obras do governo anterior. Ney Braga foi contundente ao afirmar que as construções e inaugurações se constituíam em artimanha política de Lupion, visando sua próxima eleição (PARANÁ, 1961, p. 35). Ney Braga, também apontou que o mandato de Lupion foi desorganizado e trouxe consequências maléficas para o Estado. Braga comparou os problemas da imigração aos mesmos que os portugueses causaram aos índios ao chegarem no Brasil, referiu-se às doenças que vieram com essa nova população que assentou no interior do Estado: "Além disso, diversas doenças antes desconhecidas no território paranaense, aqui surgiram trazidas pela imigração" (PARANÁ, 1961, p.35).

${ }^{10}$ A crítica que Bento Munhoz faz a Moysés Lupion, acusa que este tinha participação pela omissão nos conflitos territoriais do Estado: "A tal ponto chegou a imoralidade permitia pelo Governo anterior, senão por ele próprio fomentada, que se encontrou no assoalho do Departamento de Terras uma letra de Cr\$500.000,00 assinada por um grande magnata na aquisição de terras devolutas em favor de um funcionário do referido Departamento" (PARANÁ, 1961, p. 64). Neste trecho da mensagem, o Governador Bento Munhoz, supõe corrupção no Departamento de Terras com conivência do governo. Porém, na prática, não encontramos em documentos, nenhuma confirmação do fato. O governador Bento Munhoz e Ney Braga ganharam as eleições discursando sobre as obras promovidas por Lupion.

${ }^{11}$ Os posseiros consideram-se primeiros proprietários da área desde 1916, devido ao fato de terem sido encurralados naquele lugar após o fim da Guerra do Contestado (1912-1916). A chegada de um novo povo fez com que aumentassem as tensões, pois para além do confronto entre hábitos diferentes entre as populações, em primeiro momento se tem uma disputa pela supremacia na região do sudoeste do Paraná.

${ }^{12}$ Ney Braga critica essa medida promovida por Lupion considerando que formou-se professor de qualquer maneira sem nenhum professore habilitados para ministrar as aulas. Ney Braga quando assumiu o governo do Estado, questionou a qualidade desses profissionais. Segundo o novo governador qualquer um, na gestão de Lupion, poderia ser professor: "Milhares de pessoas sem habilitação foram nomeadas para o magistério" (PARANÁ, 1961, p. 34). Ney Braga desacreditava a gestão de Lupion, argumentando que este tanto quis construir escolas para inaugurá-las, e esqueceu-se de investir em capacitação de professores.

${ }^{13}$ Termo do Latim que significa: não há palavras, considerando Lupion pelo jornal Folha do Oeste diferente dos demais governadores pelas suas atitudes para o povo.

Recebido: nov-13 Aprovado: set-14 